\title{
Perancangan Sistem Informasi Pengukuran Kebugaran Jasmani (E-Bugar) Kementerian Kesehatan RI
}

\author{
Resti Sintya Ervina ${ }^{1}$, Tris Eryando ${ }^{2}$, Artha Prabawa ${ }^{3}$ \\ ${ }^{1}$ Departemen Biostatistik dan Kependudukan Fakultas Kesehatan Masyarakat,Program Studi \\ Informatika Kesehatan, Universitas Indonesia, Gedung A Lantai 2 Kampus UI Depok 16424, Indonesia \\ Email: ${ }^{1}$ resti.sintya.ervina@gmail.com \\ ${ }^{2}$ Departemen Biostatistik dan Kependudukan Fakultas Kesehatan Masyarakat, Universitas Indonesia, \\ Gedung A Lantai 2 Kampus UI Depok 16424, Indonesia \\ Email: ${ }^{2}$ tris.eryando@gmail.com, dr.arthaprabawa@gmail.com
}

\begin{abstract}
Lack of physical activity is one of the ten main risk factors for death. Moreover, people who are not physically active will burden the community through rising medical care costs and the loss of productivity concerned (WHO, 2018). Nowadays, the phenomenon of low physical activity also occurs in Indonesia. It turned out that something similar happened among Ministry of Health employees who were supposed to be the pioneers in carrying out physical activities. Studying such conditions, this research will propose a mobile android based application model. The purpose of this study is that Ministry of Health employees are motivated to participate in fitness measurement and then become active in physical activity. The system development method used is prototyping. The results of this study are in the form of a physical fitness measurement information system Ministry of Health which contains physical examination information, fitness measurements using the rockport method and Sports Medicine Specialist Doctors examination.
\end{abstract}

Keywords: Physical fitness, design, information systems, prototyping

\begin{abstract}
Abstrak
Kurangnya aktivitas fisik merupakan salah satu dari sepuluh faktor risiko utama kematian. Terlebih lagi, orang yang tidak aktif secara fisik akan membebani masyarakat melalui biaya perawatan medis yang terus meningkat serta hilangnya produktivitas yang bersangkutan. Dewasa ini, fenomena kegiatan aktivitas fisik yang rendah juga terjadi di Indonesia. Ternyata hal serupa terjadi pula di kalangan pegawai Kementerian Kesehatan yang seharusnya menjadi pelopor pelaksanaan aktivitas fisik. Mempelajari kondisi demikian maka penelitian ini akan mengusulkan suatu model aplikasi berbasis mobile android. Tujuan dari penelitian ini agar pegawai Kementerian Kesehatan termotivasi untuk berpartisipasi pada pengukuran kebugaran dan selanjutnya menjadi aktif melakukan aktivitas fisik. Metode pengembangan sistem yang digunakan adalah prototyping. Hasil penelitian ini berupa rancangan sistem informasi pengukuran kebugaran jasmani Kementerian Kesehatan yang berisi informasi pemeriksaan fisik, pengukuran kebugaran menggunakan metode rockport dan pemeriksaan Dokter Spesialis Kedokteran Olahraga.
\end{abstract}

Kata Kunci: Kebugaran jasmani, perancangan, sistem informasi, prototyping

\section{PENDAHULUAN}

Undang-undang Nomor 36 Tahun 2009 Pasal 80 menyatakan bahwa upaya kesehatan olahraga ditujukan untuk meningkatkan kesehatan dan kebugaran jasmani masyarakat. Peningkatan derajat kesehatan dan kebugaran jasmani masyarakat merupakan upaya dasar dalam meningkatkan prestasi belajar, kerja dan olahraga. Upaya kesehatan olahraga dilaksanakan melalui aktifitas fisik, latihan fisik dan/atau olahraga. Kesehatan didefinisikan sebagai keadaan sejahtera jasmani, mental, sosial dan spiritual kesejahteraan dan bukan hanya tidak adanya penyakit maupun kecacatan (WHO, 2001). Aktivitas fisik didefinisikan sebagai gerakan tubuh yang dihasilkan oleh otot rangka yang membutuhkan pengeluaran energi, termasuk kegiatan yang dilakukan saat bekerja, bermain, melakukan pekerjaan rumah tangga, bepergian, 
dan melakukan kegiatan rekreasi (WHO, 2018). Aktivitas fisik merupakan salah satu pola hidup yang sangat berpengaruh terhadap kenaikan prevalensi penyakit tidak menular. Fenomena ini diprediksi akan terus berlanjut. Penyakit tidak menular merupakan penyakit yang tidak infeksius dan sulit sekali disembuhkan apabila kondisi penyakit sudah kronis karena itu upaya terbaik yang dapat dilakukan dengan cara mengendalikan faktor risiko terjadinya penyakit tidak menular tersebut. Berdasarkan WHO, kurangnya aktivitas fisik merupakan salah satu dari sepuluh faktor risiko utama kematian. Orang yang tidak aktif secara fisik memiliki risiko 20\% hingga $30 \%$ peningkatan dari semua penyebab kematian dibandingkan dengan mereka yang melakukan setidaknya 150 menit aktivitas fisik intensitas sedang per minggu. Menurut hasil Riset Kesehatan Dasar, proporsi aktivitas fisik kurang naik dari 26,1\% menjadi 33,5\% dibandingkan Tahun 2013.

Berbagai faktor risiko penyakit tidak menular diantaranya adalah merokok dan keterpaparan terhadap asap rokok, diet/pola makan tidak sehat, kurang aktivitas fisik, konsumsi minuman beralkohol, dan riwayat keluarga (keturunan). Berbagai upaya pemerintah untuk mengatasi tingginya kematian akibat penyakit tidak menular, khususnya Kementerian Kesehatan yang telah mencanangkan Gerakan Masyarakat Hidup Sehat (GERMAS). Berdasarkan Instruksi Presiden Nomor 1 Tahun 2017, Gerakan Masyarakat Hidup Sehat bertujuan untuk meningkatkan kesadaran masyarakat menjalankan pola hidup sehat serta meninggalkan kebiasaan dan perilakukurang sehat. Germas terdiri dari 3 (tiga) kegiatan utama yang dikampanyekan kepada masyarakat antara lain 1) melakukan aktivitas fisik minimal 30 menit setiap hari; 2) Makan buah dan sayur setiap hari; dan 3) Memeriksa kesehatan secara rutin.

Kementerian Kesehatan melalui Direktorat Kesehatan Kerja dan Olahraga sebagai pelopor pelaksana Germas terkait aktivitas fisik telah melaksanakan upaya kesehatan olahraga guna meningkatkan kualitas kesehatan pegawainya. Pegawai Kementerian Kesehatan sebagai unsur pelaksana pemerintahan negara, harus memiliki kondisi yang sehat bugar dan produktif, agar dapat bekerja dengan maksimal dalam melayani masyarakat. Upaya kesehatan olahraga yang telah dilakukan antara lain melalui kegiatan senam bersama pada setiap hari jumat pagi, bazar buah dan sayur setiap 1 bulan sekali, kegiatan peregangan setiap hari kerja pukul 10.00 dan 14.00 , serta pelaksanaan pengukuran kebugaran jasmani yang dilakukan secara berkala kepada seluruh pegawai minimal 3 bulan sekali. Pelaksanaan pengukuran kebugaran dijadikan sebagai upaya preventif terjadinya penyakit tidak menular.

Kementerian kesehatan telah melaksanakan pengukuran kebugaran jasmani menggunakan tes lapangan 1,6 KM metode Rockport karena mempertimbangkan aspek kemudahannya, biaya yang dikeluarkan tidak banyak dan dapat dilakukan secara masal dan lebih efisien. Tes Rockport valid terhadap tes Bruce yang merupakan baku emas pengukuran kebugaran jantung paru (Budiman, 2017). Oleh karena itu tes Rockport cocok untuk digunakan baik di Kementerian Kesehatan maupun masyarakat.

Berdasarkan hal tersebut, akan dikembangkan sebuah perancangan sistem informasi kebugaran jasmani Kementerian Kesehatan yang selanjutnya disebut e-Bugar dengan tujuan untuk mengoptimalisasi hasil pengukuran kebugaran sehingga dapat memotivasi pegawai untuk ikut pengukuran kebugaran jasmani. Sistem ini dapat dimanfaatkan sebagai alat deteksi dini, monitoring kesehatan pegawai, notifikasi/ peringatan kesehatan, pencatatan dan pelaporan hasil pengukuran kebugaran jasmani serta sebagai bahan penunjang pengambilan kebijakan. Melalui sistem informasi ini diharapkan data hasil pengukuran kebugaran yang terkumpul dapat dimanfaatkan secara maksimal serta dapat meningkatkan kesehatan pegawai Kementerian Kesehatan.

\section{METODE}

Penelitian ini dilakukan di Kementerian Kesehatan yang beralamat di Jalan H.R. Rasuna Said Blok X5 Kav. 4-9 Jakarta Selatan. Kegiatan pengukuran kebugaran jasmani ini dilaksanakan oleh satker Direktorat Kesehatan Kerja dan Olahraga. Teknik pengumpulan data yang dibutuhkan pada penelitian ini menggunakan cara observasi dan studi pustaka.

Metode pengembangan perangkat lunak yang digunakan untuk merancang Sistem Informasi Pengukuran Kebugaran Jasmani menggunakan metode prototyping. Metode ini cocok digunakan untuk mengembangkan sebuah perangkat yang akan dikembangkan kembali (Mustika dkk, 2017). Metode ini juga cocok untuk sistem atau perangkat lunak yang bersifat customize (Susanto dan Andriana, 
2016). Metode ini tepat digunakan karena dapat menghasilkan rancangan sistem informasi sementara, desain yang cepat dan memberikan visual dari sistem yang diusulkan (Litchter dkk, 1994). Dengan metode prototyping, pengguna dan pengembang dapat saling berkomunikasi untuk menentukan pemodelan sistem yang akan menjadi dasar pengembangan sistem operasi, pengguna dapat ikut terlibat secara aktif sehingga sistem yang dibuat sesuai dengan keinginan dan harapan pengguna dan sistem yang dibangun sesuai dengan kebutuhan yang ada (Buana T. Dkk, 2017). Berdasarkan metode prototyping, tahapantahapan yang dilakukan pada penelitian ini antara lain: 1) analisis kebutuhan sistem; 2) perencanaan sistem; 3) perancangan sistem, dan 4) implementasi.

\section{HASIL}

Hasil penelitian ini diuraikan bagaimana proses pengukuran kebugaran jasmani dilakukan. Gambaran kondisi ini didapat dari hasil studi kualitatif dengan metode wawancara, observasi dan studi literatur. Selain itu akan dijelaskan tahapan pengembangan sistem yang mengacu pada metode prototyping yaitu analisis kebutuhan sistem, perencanaan sistem.

\section{Analisis Kebutuhan Sistem}

Pengukuran kebugaran jasmani merupakan salah satu upaya untuk meningkatkan stamina dan status kesehatan seseorang dengan cara melakukan aktivitas fisik dan latihan fisik/olahraga. Upaya ini telah dilaksanakan oleh Direktorat Kesehatan Kerja dan Olahraga, Kementerian Kesehatan dengan sasaran seluruh pegawai Kementerian Kesehatan yang belokasi di Jl. H.R. Rasuna Said Blok X5 Kav 4-9 Jakarta Selatan. Pengukuran kebugaran jasmani dilakukan dihalaman kantor Kementerian Kesehatan dengan menggunakan metode rockport. Metode ini mengharuskan peserta untuk melakukan jalan cepat sejauh 1,6 KM yang kemudian akan dihitung waktu tempuh peserta dalam menit dan detik. Hasil pengukuran tersebut kemudian dicatat pada Kartu Menuju Bugar (KMB). Kartu tersebut harus dibawa setiap kali akan melakukan pengukuran kebugaran. Rekapitulasi hasil pengukuran kebugaran diserahkan kepada pemangku kebijakan dalam bentuk excel.

Dari gambaran tersebut dapat dilihat bahwa pemrosesan data dan informasi memiliki banyak kendala seperti sulitnya bagi peserta untuk dapat memantau kebugarannya secara berkala sehingga sulit untuk mendeteksi penyakit tidak menular lebih awal. Pemantauan dapat berjalan dengan baik dipengaruhi oleh kesadaran pegawai untuk mengikuti pengukuran kebugaran. Selain itu hasil rekapitulasi kebugaran jasmani pegawai membutuhkan waktu yang lama untuk diolah menjadi laporan yang nantinya akan digunakan sebagai bahan pendukung pengambilan keputusan oleh pemangku kebijakan.

Sistem informasi kebugaran jasmani harus dapat mengakomodir kebutuhan dari 4 pengguna sistem yang terlibat dalam proses pengukuran kebugaran jasmani yaitu admin, pegawai Kementerian Kesehatan, Unit Pelayanan Kesehatan (UPK) Kementerian Kesehatan, Direktur Kesehatan Kerja dan Olahraga dan Direktur Jenderal Kesehatan Masyarakat.

\section{Perencanaan Sistem}

Proses perencanaan dibuat berdasarkan hasil yang diperoleh dari studi kualitatif. Hasil yang diperoleh dibuat kedalam bentuk flowchart. Flowchart tersebut menggambarkan urutan proses pengukuran kebugaran secara mendetail. Pelaksanaan pengukuran kebugaran jasmani dilakukan diluar ruangan sehingga sistem yang dirancang berbasis android agar memudahkan pengguna untuk mengaksesnya.

Proses pengukuran kebugaran dimulai dengan pegawai mendatangi tempat pengukuran kebugaran. Pegawai akan diminta untuk menginstall aplikasi e-Bugar pada handpone masing-masing. Kemudian pegawai diminta untuk login menggunakan NIP dan password. Setelah masuk ke dalam aplikasi e-Bugar, pegawai diminta mengisi Physical Activity Readiness (Par-Q) yang terdiri dari 7 pertanyaan. Par-Q adalah alat skrining diri sederhana yang dapat digunakan oleh siapa saja yang berencana untuk memulai program latihan. Pengisian ini dilakukan untuk melihat kemungkinan risiko berolahraga untuk seseorang berdasarkan riwayat kesehatannya dan melihat latihan yang paling ideal untuk dilakukan (Quinn, 2019). Proses selanjutnya adalah pengisian pemeriksaan fisik yang terdiri dari pemeriksaan berat badan, tinggi badan, tekanan darah, gula darah sewaktu dan kolesterol sewaktu. Data pemeriksaan ini sangat penting karena dapat digunakan sebagai deteksi dini penyakit tidak menular yang perlu dipantau secara berkala. Masalah yang ada adalah data tersebut dicatat pada Kartu Menuju Bugar (KMB) yang kemungkinan untuk kehilangan data sangatlah besar. 
Resti Sintya Ervina, Tris Eryando, dan Artha Prabawa. Perancangan Sistem Informasi Pengukuran Kebugaran ...

Setelah melakukan skrining dengan cara pengisian Par-Q dan pemeriksaan fisik, pegawai yang tidak memenuhi syarat melakukan konsultasi ke dokter SpKO untuk pemeriksaan lebih lanjut. Sedangkan untuk pegawai yang memenuhi syarat dapat langsung melakukan pengukuran kebugaran jasmani. Hasil pengukuran akan otomatis tercatat di dalam aplikasi e-Bugar dan akan ada SMS notifikasi kepada pegawai yang berisi hasil kebugaran, rekomendasi latihan fisik dan catatan dari dokter SpKO. Proses pengukuran kebugaran jasmani dapat dilihat pada Gambar 1.

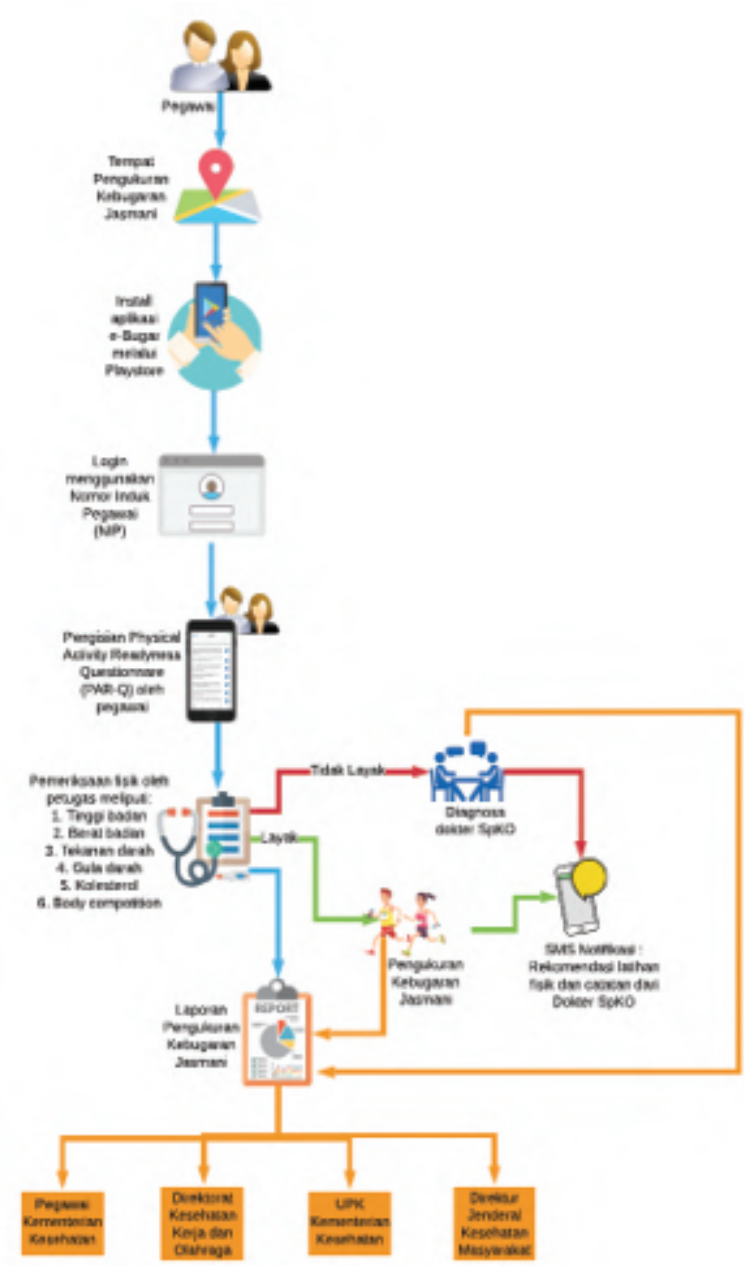

Gambar 1. Alur Pengukuran Kebugaran Jasmani

\section{Perancangan Sistem}

Perancangan sistem melibatkan identifikasi dan deskripsi abstraksi sistem perangkat lunak yang mendasar beserta hubungan-hubungannya. ${ }^{11}$ Rancangan tersebut dibagi kedalam beberapa bagian yaitu perancangan Context Diagram, Data Flow Diagram (DFD), Entity Relationship Diagram (ERD) dan Table Relationship Diagram (TRD).

\section{Context Diagram (CD)}

Pada konteks diagram dapat dilihat bagaimana sistem dirancang secara keseluruhan dan menggambarkan seluruh entity yang terkait sehingga dapat terlihat data yang mengalir pada input, proses dan outputnya. Diagram konteks memperlihatkan alur data yang mengalir dari entitas sumber ke entitas proses dan entitas tujuan (11). Berdasarkan diagram konteks pada Gambar 2 dapat dilihat bahwa terdapat empat entitas yang berhubungan dengan Sistem Informasi Kebugaran Jasmani yaitu pegawai Kementerian Kesehatan, Direktorat Kesehatan Kerja dan Olahraga, Direktur Jenderal Kesehataan Masyarakat dan Unit Pelayanan Kesehatan (UPK) Kementerian Kesehatan.

\section{Data Flow Diagram (DFD)}

Data Flow Diagram level 1 menjabarkan rincian dari proses yang ada pada diagram konteks yang terdiri dari proses login, pengisian Par-Q, pemeriksaan fisik, pengukuran kebugaran, data pemeriksaan spesialis, sms notifikasi, laporan kebugaran pegawai. DFD level 1 dapat dilihat pada Gambar 3.

\section{Entity Relationship Diagram (ERD)}

Entity Relationship Diagram digunakan untuk memperlihatkan hubungan antar entitas dalam sistem. ERD juga menggambarkan bagaimana hubungan antara entitas yang ada dalam sistem beserta atribut-atribut yang dimilikinya. Hubungan antar entitas yang terjadi dalam Sistem Informasi Pengukuran Kebugaran Jasmani dapat dilihat pada Gambar 4.

\section{Table Relationship Diagram (TRD)}

Pada Table Relationship Diagram dapat diketahui hubungan antar tabel yang ada pada rancangan Sistem Informasi Kebugaran Jasmani. Hubungan antar tabel dalam Sistem Informasi Pengukuran Kebugaran Jasmani dapat dilihat pada Gambar 5.

\section{PEMBAHASAN}

Analisa dalam pembahasan menguraikan secara tepat dan argumentatif hasil penelitian dengan teori dan hasil penelitian terdahulu. 


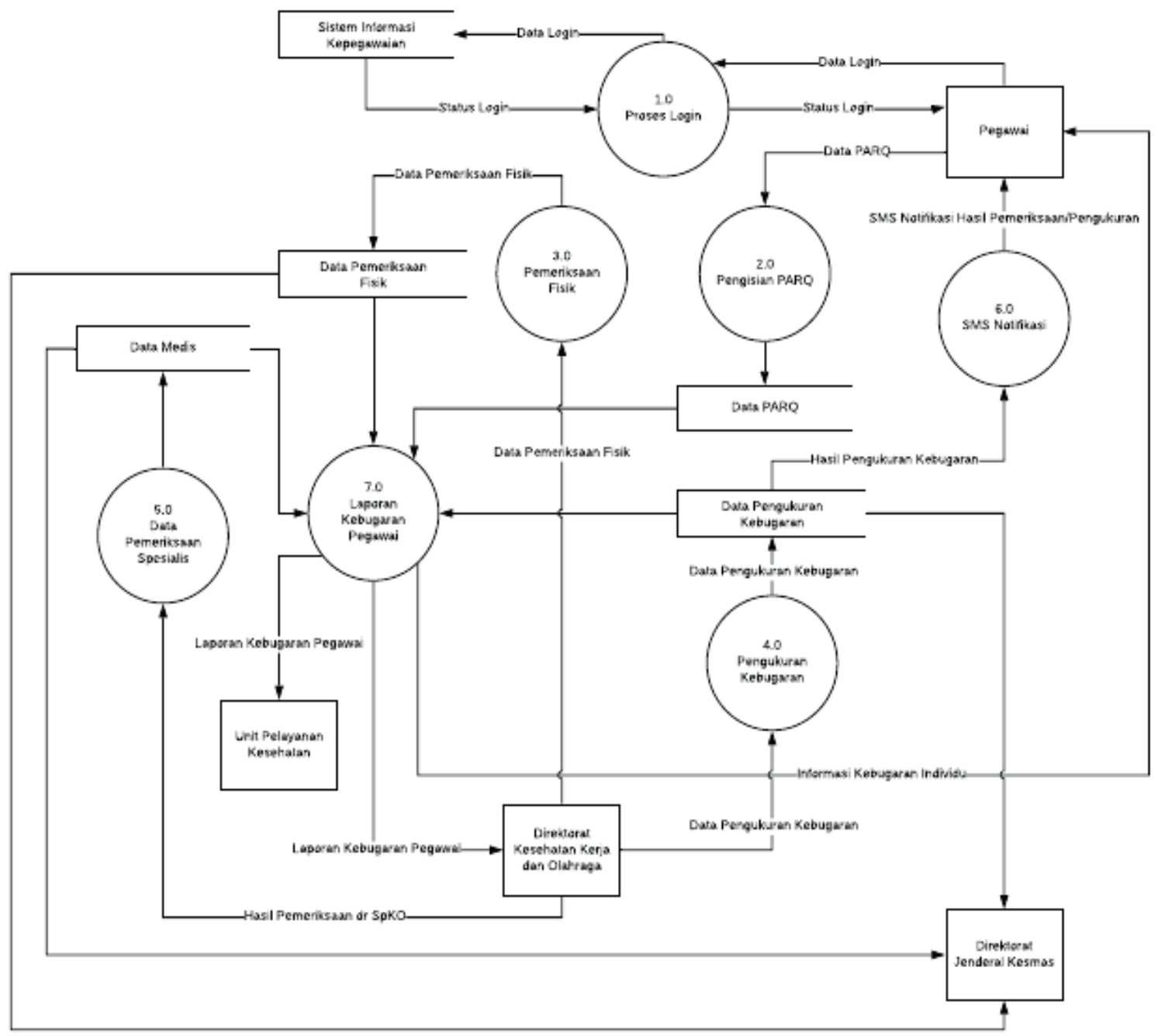

Gambar 2. Context Diagram (CD)

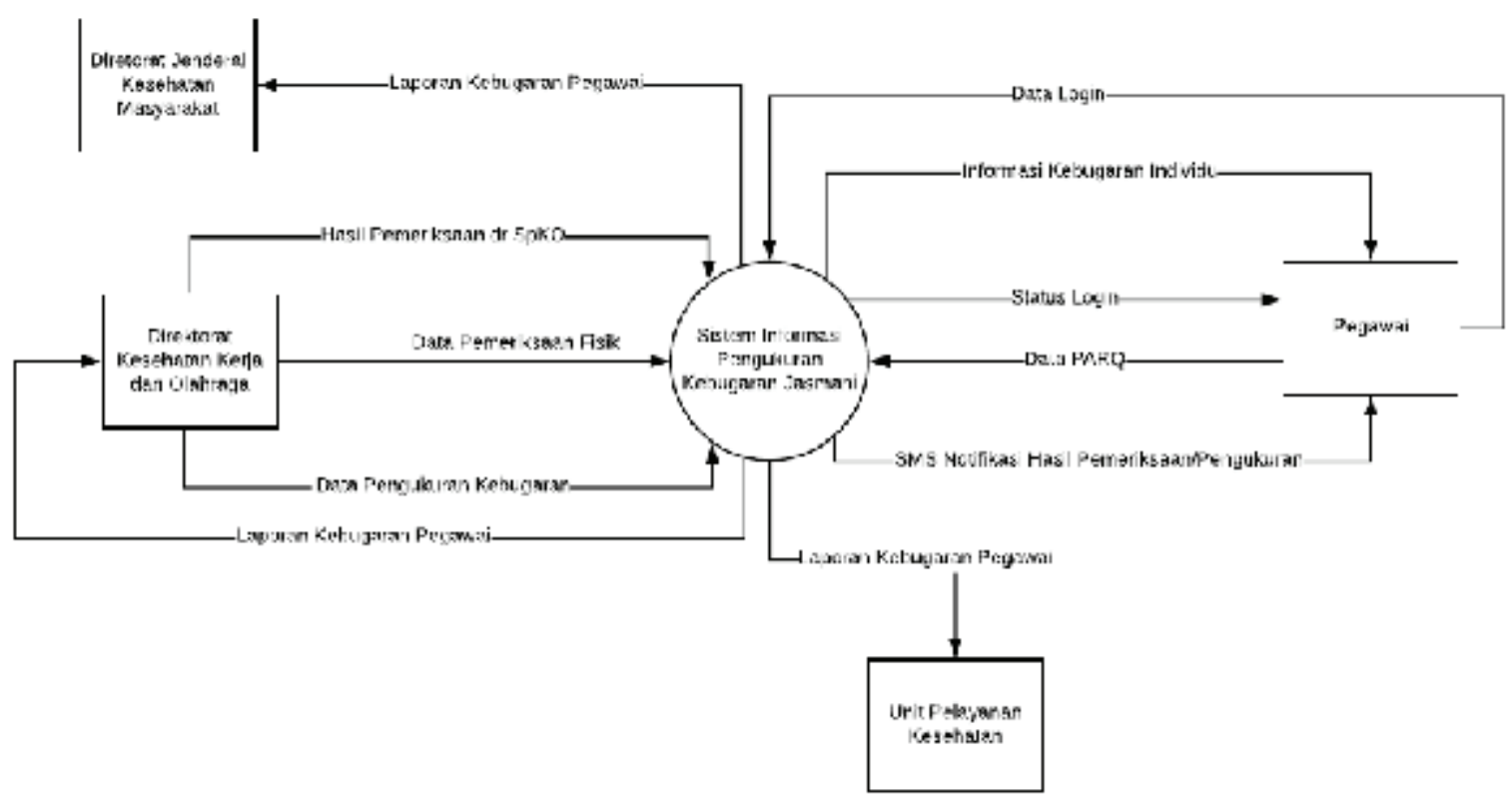

Gambar 3. Data Flow Diagram (DFD) 


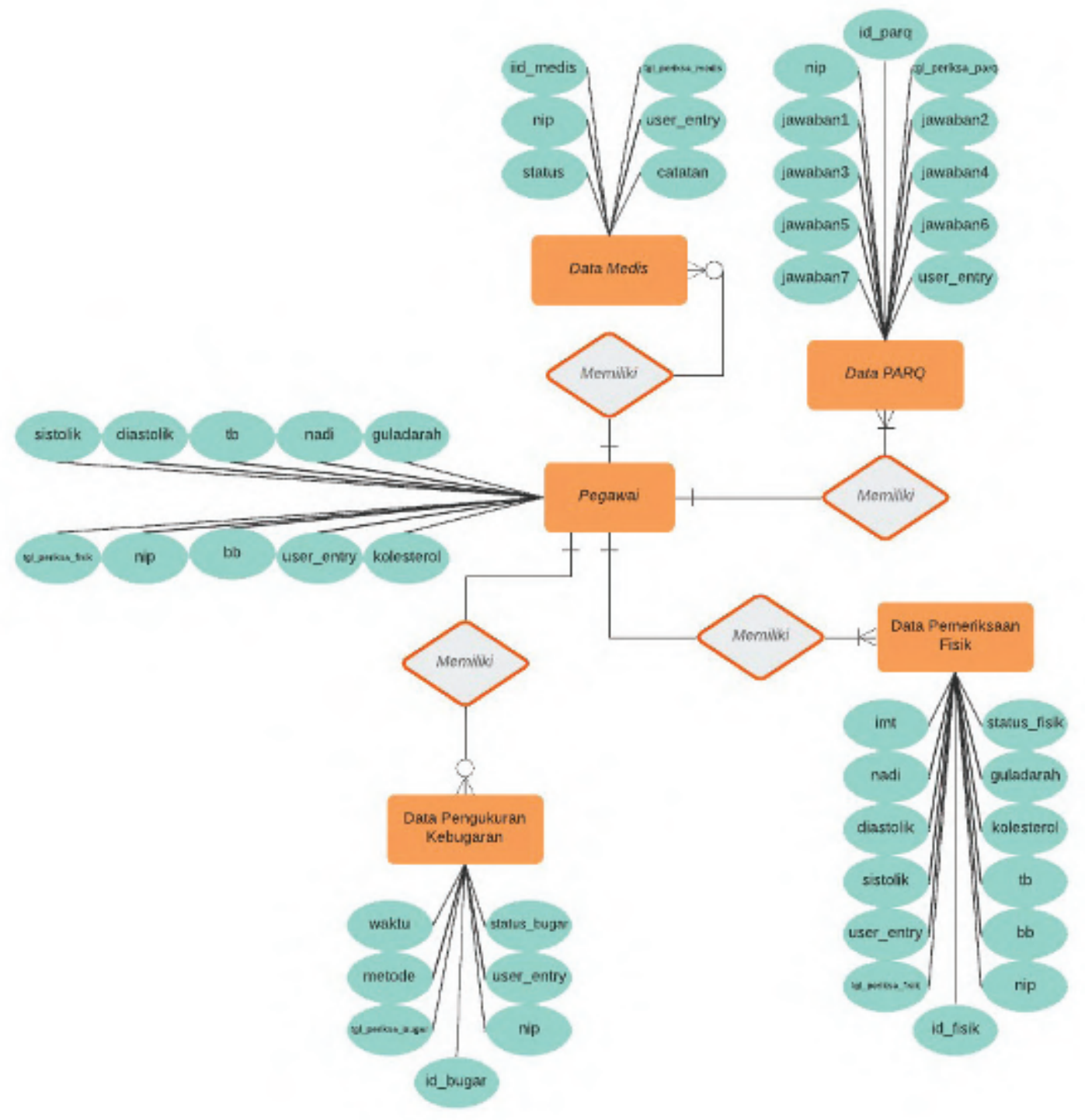

Gambar 4. Entity Relationship Diagram (ERD)

\section{Implementasi}

Tahap implementasi merupakan tahapan terakhir pada penelitian ini. Pada tahap ini desain sistem diterjemahkan ke dalam form, kode dan laporan. Implementasi dilakukan sesuai dengan kebutuhan yang telah dilakukan pada tahap analisis dan perancangan.

\section{PEMBAHASAN}

Sistem informasi pengukuran kebugaran jasmani (e-Bugar) merupakan aplikasi berbasis android yang dirancang untuk mencatat, mengolah, melaporkan dan menganalisis pelaksanaan pengukuran kebugaran jasmani. Untuk melihat gambaran aplikasi e-Bugar secara lebih jelas, dapat dilihat pada antarmuka sistem yang sudah dibuat. Aplikasi E-Bugar ini terbagi ke dalam 2 model aplikasi yaitu model aplikasi web dan model aplikasi mobile android. Model aplikasi web berisi Daftar Hasil Pengukuran Kebugaran Pegawai, Laporan Rekapitulasi Status Kebugaran, Laporan Rekapitulasi Indeks Massa Tubuh (IMT) dan Laporan Jumlah Pegawai yang Melakukan Pengukuran Kebugaran Jasmani, sedangkan untuk model aplikasi mobile android berisi Login, Pengisian Par-Q, Pemeriksaan Fisik, Pengukuran Kebugaran dan Pemeriksaan Dokter Spesialis Kedokteran Olahraga. Bentuk antarmuka dari masing-masing menu adalah sebagai berikut: 


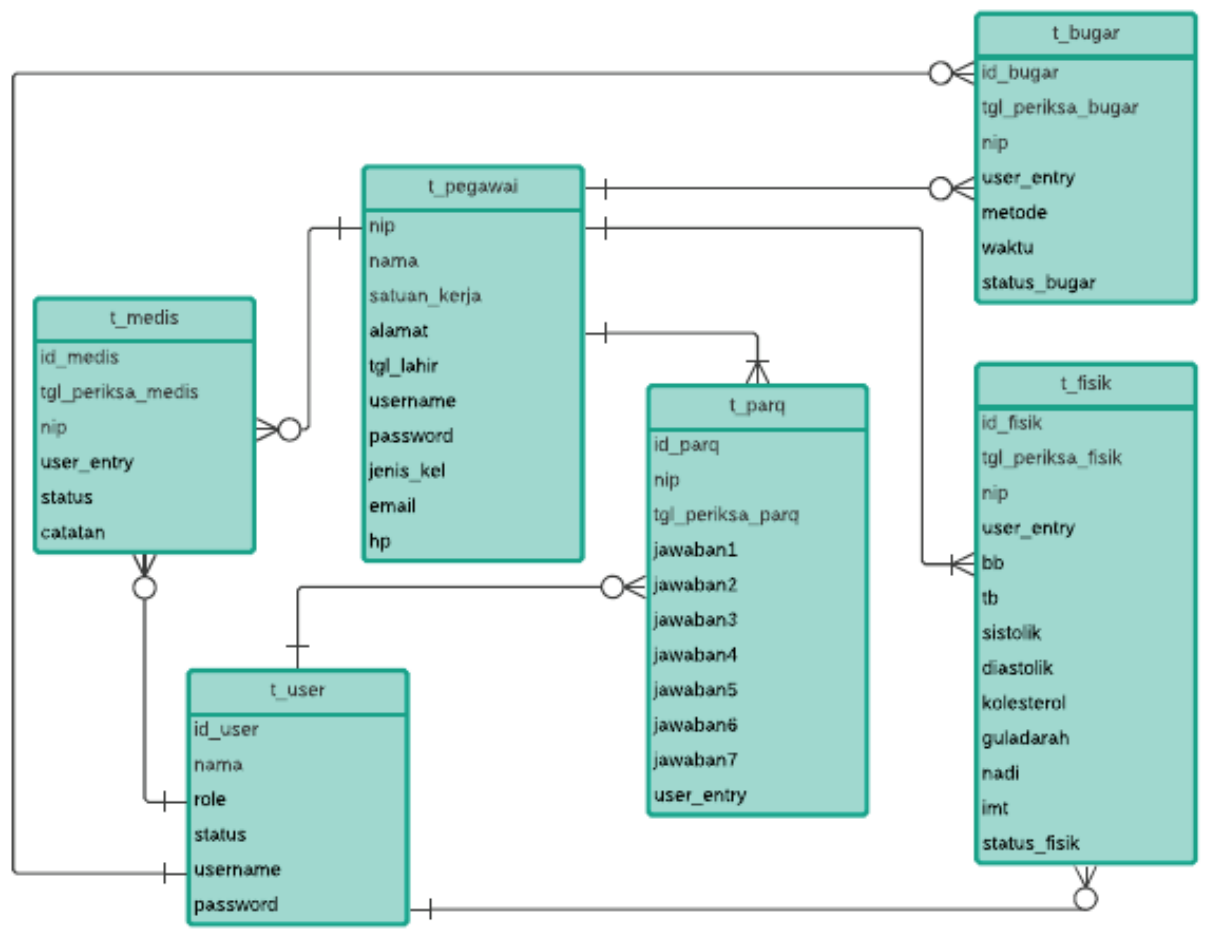

Gambar 5. Table Relationship Diagram (TRD)

\section{Menu Login}

Form login dapat diakses setelah pengguna menginstall aplikasi e-Bugar melalui Playstore. Username dan password yang digunakan adalah NIP dari masing-masing pegawai sehingga pengguna tidak perlu melakukan pendaftaran terlebih dahulu.
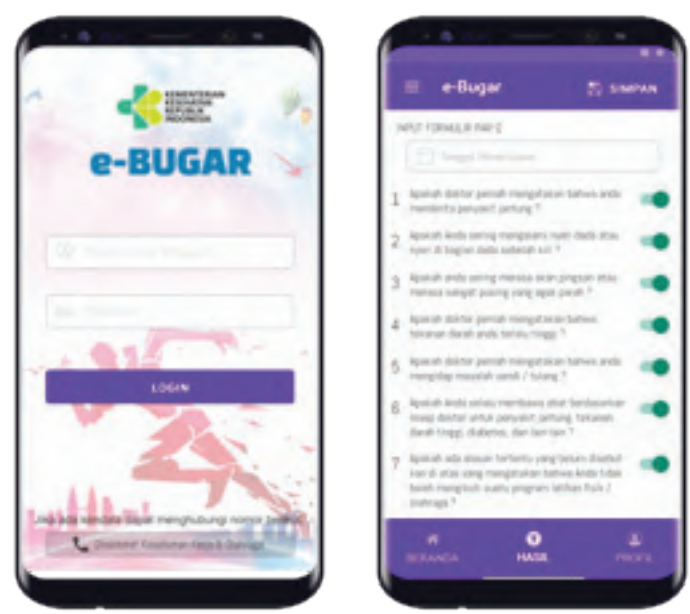

Gambar 6. Menu Login dan Par-Q

\section{Menu Pengisian Par-Q}

Pada halaman ini menampilkan 7 pertanyaan yang berfungsi sebagai alat skrining diri sederhana sebelum memulai program latihan. Pengisian ini dilakukan untuk melihat bagaimana riwayat kesehatan dari pegawai yang akan melakukan pengukuran kebugaran jasmani tersebut. Menu pengisian Par-Q dapat dilihat pada Gambar 6 .
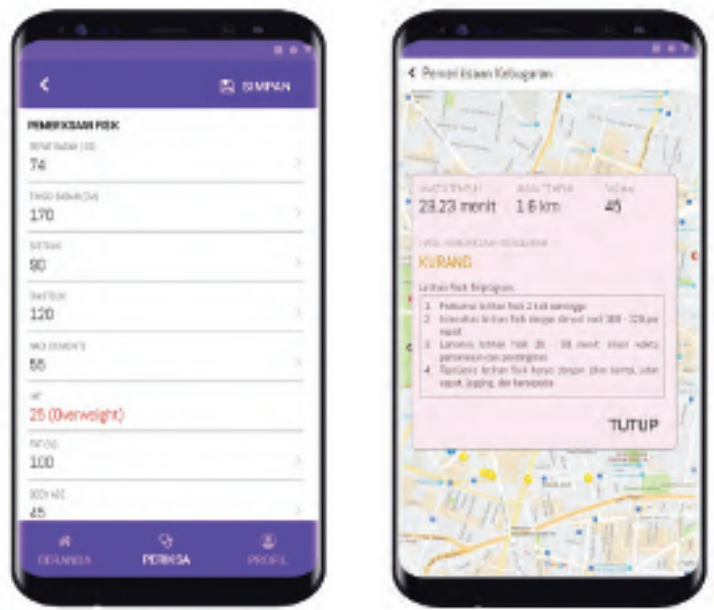

Gambar 7. Menu Pemeriksaan Fisik dan Pengukuran Kebugaran 
Resti Sintya Ervina, Tris Eryando, dan Artha Prabawa. Perancangan Sistem Informasi Pengukuran Kebugaran ...

\section{Menu Pemeriksaan Fisik}

Pemeriksaan fisik merupakan pemeriksaan untuk melihat apakah pegawai layak untuk melakukan pengukuran kebugaran. Pemeriksaan fisik yang dilakukan meliputi pemeriksaan berat badan, tinggi badan, tekanan darah, IMT, body competition dan ada juga pemeriksaan laboratorium yang meliputi gula darah sewaktu dan kolesterol sewaktu. Menu pemeriksaan fisik dapat dilihat pada Gambar 7.

\section{Menu Pengukuran Kebugaran}

Setelah pegawai dinyatakan layak untuk melakukan pengukuran kebugaran jasmani kemudian peserta melakukan lari / jalan cepat sejauh 1,6 KM. Hasil pengukuran tersebut yaitu waktu tempuh, jarak tempuh dan VO2Max yang kemudian di konversi sehingga menghasilkan status kebugaran. Pada Gambar 7 dapat dilihat antarmuka menu pengukuran kebugaran.

\section{Menu Pemeriksaan Dokter Spesialis Kedokteran Olahraga \\ Halaman pemeriksaan dokter spesialis kedokteran olahraga berfungsi untuk menampilkan catatan dari dokter spesialis kesehatan olahraga terhadap pegawai yang mendapatkan hasil tidak layak mengikuti pengukuran kebugaran jasmani pada saat pengisian Par-Q dan pemeriksaan fisik untuk dapat dilakukan diagnosa mandalam.}

Menu Daftar Pegawai yang melakukan Pengukuran Kebugaran

Menu ini menghasilkan daftar pegawai yang telah melaksanakan pengukuran pegawai. Pada halaman ini terdapat beberapa fungsi seperti mencetak laporan, export laporan kedalam bentuk excel dan memfilter laporan berdasarkan satuan kerja/nama pegawai/tanggal pengukuran. Antarmuka yang menampilkan daftar pegawai yang melakukan pengukuran kebugaran dapat dilihat pada Gambar 8 .

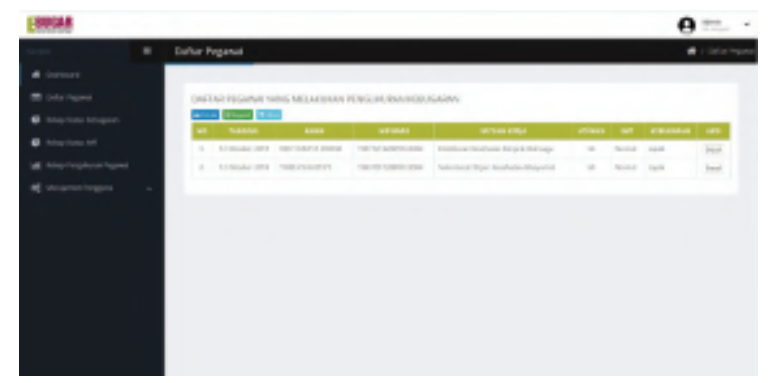

Gambar 8. Daftar pegawai yang melakukan pengukuran kebugaran

\section{Menu Laporan Rekapitulasi Status Kebugaran}

Menu laporan ini menampilkan informasi status kebugaran pegawai per satuan kerja. Laporan ini bisa dilihat dalam bentuk diagram ataupun tabel. Laporan rekapitulasi status kebugaran dapat dilihat pada Gambar 9.

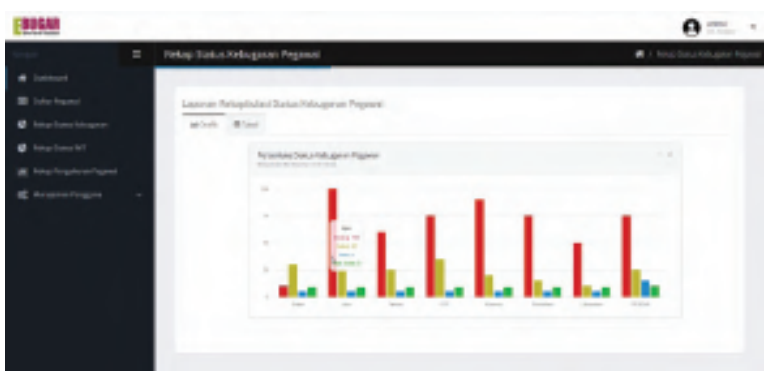

Gambar 9. Laporan Rekapitulasi Status Kebugaran

\section{Menu Laporan Jumlah Pegawai yang Melakukan Pengukuran Kebugaran Jasmani}

Pada halaman ini disajikan berbagai laporan dalam bentuk diagram. Diagram yang ditampilkan antara lain presentase Indeks Massa Tubuh (IMT) pegawai, presentase pegawai yang melakukan pengukuran dan presentase kebugaran pegawai dibagi per kategori baik, cukup, kurang dan kurang sekali. Laporan tersebut dapat dilihat pada gambar 10 .

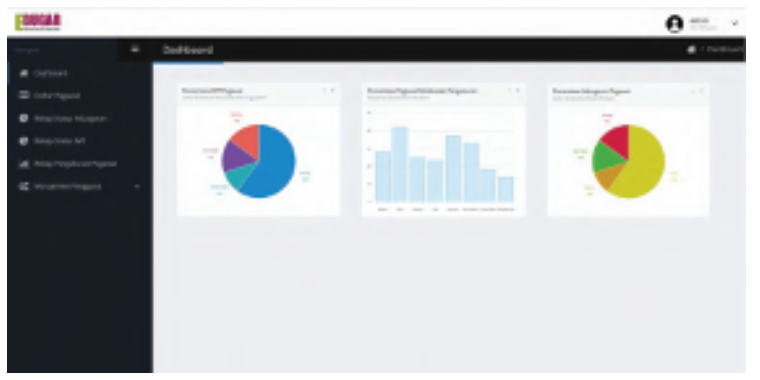

Gambar 10. Menu laporan jumlah pegawai yang melakukan pengukuran kebugaran

\section{SIMPULAN}

Penelitian ini menghasilkan prototype sistem informasi kebugaran jasmani (e-Bugar) yang mencakup pengisian Physical Activity Readiness (Par-Q), pemeriksaan fisik (berat badan, tinggi badan, tekanan darah, gula darah sewaktu dan kolesterol sewaktu) dan pengukuran kebugaran jasmani menggunakan metode Rockport. Sistem informasi ini dapat dikembangkan oleh organisasi 
agar dapat dimanfaatkan oleh masyarakat umum. Sistem Informasi Pengukuran Kebugaran Jasmani dikembangan dengan membangun fitur-fitur yang sesuai dengan kebutuhan pengguna. Dengan beberapa pengembangan, sistem ini dapat digunakan oleh masyarakat umum. Tahapan deployment delivery \& feedback perlu dilakukan untuk mengetahui kekurangan aplikasi. Implementasi aplikasi e-Bugar dengan segala keterbatasannya memerlukan pemeliharaan dan pengembangan lebih lanjut agar sistem dapat menyesuaikan dengan kebutuhan di masa yang akan datang.

\section{DAFTAR PUSTAKA}

Buana Tunggang Dewi T, Marthasari GI, Risqiwati D. Rancang Bangun Dan Implementasi Website E-Commerce UKM GS4 Malang Menggunakan Metode Prototyping. Jurnal Universitas Muhammadiya. Malang. 2017;110.

Budiman I, Aprijana I, Iskandar D. Penggunaan Tes Lapangan 1,6 KM Metoda Rockport Untuk Pengukuran Kebugaran Jantung-Paru Dengan Baku Emas Treadmill Metoda Bruce. Jurnal Sains Keolahragaan dan Kesehatan. Bandung. 2017; 2(2):38.

Hozisah D. Perancangan Sistem Informasi Pelayanan Antenatal Terpadu ( SIPAT ). Jurnal MKMI. Makassar. 2015; (September):189-96.

Joanda AD, Priyandari Y, Zakaria R. Perancangan Sistem Informasi Manajemen Layanan Jasa Teknologi dan Kerjasama di Lembaga DEF. Jurnal Sistem Informasi. Surakarta. 2014; $10(2)$.
Kementerian Kesehatan. Laporan Nasional Riset Kesehatan Dasar 2018. Jakarta. 2018.

Lichter H, Schneider-Hufschmidt M, Zullighoven H. Prototyping in Industrial Software ProjectsBridging the Gap Between Theory and Practice. IEEE Trans Softw Eng. 1994; 20(11):825-32.

Mustika, E. Sugara, M. Pratiwi. Pengembangan Media Pembelajaran Interaktif dengan Menggunakan Metode Multimedia Development Life Cycle. Jurnal Online Informatika. Palembang. 2017; 2(2):121 - 126 .

Nugraha W, Syarif M. Penerapan Metode Prototype dalam Perancangan Sistem Informasi Penghitungan Volume dan Cost Penjualan Minuman Berbasis Website. Jurnal Sistem Informasi Musirawas. Lubuklinggau. 2018; $3(2)$.

Pressman RS. Software Quality Engineering: A Practitioner's Approach. New York. 2014. 1-193.

Susanto R, Andriana AD. Perbandingan Model Waterfall dan Prototyping untuk Pengembangan Sistem Informasi. Jurnal Majalah Ilmiah UNIKOM. 2016; 14(1). WHO. A Public Health Approach to Mental Health. 2001. [Diakses 13 Oktober 2019]. Available at: http://www.who.int/whr/2001/ en/whr01_ch1_en.pdf

WHO. Global Action Plan on Physical Activity 2018 - 2030. 2018. Switzerland. 